\title{
GERMINAÇÃO DE SEMENTES E CRESCIMENTO INICIAL DE MUDAS DE Campomanesia adamantium Camb.: EFEITO DA LAVAGEM, TEMPERATURA E DE BIOESTIMULANTES ${ }^{1}$
}

\author{
SILVANA DE PAULA QUINTÃO SCALON², ANDRÉA ALVES DE LIMA4; \\ HOMERO SCALON FILHO ${ }^{5}$, MARIA DO CARMO VIEIRA ${ }^{2,3 .}$
}

\begin{abstract}
RESUMO - O objetivo neste trabalho foi avaliar o potencial germinativo das sementes de Campomanesia adamantium e o crescimento inicial das plantas. Para avaliar a germinação foram realizados dois testes de processamento das sementes. No primeiro teste foram realizados os seguintes tratamentos: 1) extração das sementes, lavagem em água corrente e secagem à temperatura ambiente durante 3 dias; 2) lavagem em água corrente e semeadura logo em seguida e 3) extração das sementes dois dias após a colheita, lavagem e imersão em água por 24 horas. No segundo teste, os tratamentos foram: 1) lavagem e secagem à temperatura ambiente durante nove dias; 2) extração das sementes dos frutos armazenados à temperatura ambiente por nove dias, lavagem em água corrente e semeadura logo em seguida e 3) extração das sementes dos frutos armazenados por oito dias, lavagem e imersão em água por 24 horas. A incubação foi em BOD a 20/30, 18 e $30^{\circ} \mathrm{C}$ e em viveiro. As plântulas receberam duas aplicações de bioestimulante $(0,2 \mathrm{~mL} /$ planta) aos 80 e 90 dias após a semeadura; ácido giberélico 50, 100 e 150 $\mathrm{mg} \mathrm{L}^{-1}$ e as plantas sem nenhum tratamento serviram como testemunha. A germinação das sementes aos três dias após a retirada do fruto é elevada e não varia em função do processamento e temperatura de incubação. Quando mantidas no fruto as sementes perdem a qualidade fisiológica. Considerando o lento crescimento das plantas de guavira, sugere-se que um tratamento hormonal com aplicação de bioestimulante é uma prática eficiente na produção de mudas dessa espécie
\end{abstract}

Termos para indexação: guavira, cerrado, fruta nativa.

\section{SEED GERMINATION AND INITIAL GROWTH OF Campomanesia adamantium Camb SEEDLINGS: EFFECTS OF WASHING, TEMPERATURE AND BIOSTIMULANT}

\begin{abstract}
The objective of this study was to evaluate the germination potential of Campomanesia adamantium seeds and initial seedling growth. To evaluate the germination, two tests of seed processing were carried out. In the first test the following treatments were accomplished: 1)seeds extraction, washing in running water and drying at ambient temperature for 3 days; 2) washing in running water and sowing soon after and 3) seed extraction two days after the harvest, washing and immersion in water for 24 hours. In the second tests, the treatments were: 1) washing and drying at ambient temperature for nine days; 2) seed extraction from the fruits stored at ambient temperature for nine days, washing in running water and sowing soon after and 3) seed extraction from the fruits stored for eight days, washing and immersion in water for 24 hours. The seedlings received 2 applications of
\end{abstract}

\footnotetext{
${ }^{1}$ Submetido em 12/05/2008. Aceito para publicação em 29/11/2008.

${ }^{2}$ Professores da Universidade Federal da Grande Dourados/Faculdade de Ciências Agrárias, Rodovia Dourados, Itahum, Km 12, CEP:79804970, Dourados, MS. silvana.scalon@ufgd.edu.br;
}

${ }^{3}$ Bolsista de produtividade $\mathrm{CNPq}$;

${ }^{4}$ Acadêmica de Ciências Biológicas - UFGD;

${ }^{5}$ Professor da Universidade Estadual de Mato Grosso do Sul, Dourados, MS 
bio stimulant (0.2ml/ plant) 80 and 90 days after sowing; gibberellic acid 50, 100 and $150 \mathrm{mg} \mathrm{L}^{-1}$ and the plants without any treatment served as the control. The seed germination in three days after fruit extraction was high and did not have significant interaction in function of processing and incubation temperature. When kept in the fruit, the seeds lose their physiological quality. Considering the slow growth of guavira plants, hormonal treatment is suggested with application of bioestimulants as an efficient practice in the seedling production of this species.

Index terms: guavira, cerrado, native fruit,.

\section{INTRODUÇÃO}

A ocorrência das espécies nativas na região Centro - Oeste e especialmente em Mato Grosso do Sul é pouco conhecida, pois, são escassas as pesquisas científicas sobre levantamentos botânicos e testes de propagação e produção de mudas. A cobertura vegetal, que originalmente ocupava a maior parte do território brasileiro, vem historicamente cedendo espaço para atividades antrópicas como a agricultura e a urbanização. Nesse cenário, grandes áreas cobertas no passado por florestas nativas vêm se transformando em paisagens caracterizadas pela fragmentação florestal, especialmente nas regiões mais desenvolvidas do País, como Sudeste e Sul, mas avança rapidamente para o Centro-Oeste e Norte, resultado principalmente da expansão da fronteira agrícola (Martins e Silva, 2001).

Nesse contexto, a região do Cerrado vem sendo destruída, e segundo levantamento bibliográfico realizado por Melchior et al. (2006), são necessários estudos sobre a propagação e exploração racional das espécies frutíferas nativas dessa região, com características organolépticas interessantes e de potencial econômico.

A guavira ou gabiroba (Campomanesia sp.) é originária do Brasil, com grande abundância na região do Cerrado. Entretanto a cada ano ela vem se tornando menos abundante em seu habitat. Para agravar essa situação, não há registro do cultivo dessa espécie, sendo encontrada apenas como nativa. As folhas e os frutos de Campomanesia possuem algumas propriedades medicinais com ação antiinflamatória, antidiarréica e antisséptica das vias urinárias, utilizada contra reumatismo e como desobstruente do fígado (Penna, 1946; Rodrigues e Carvalho, 2001).

Pesquisas vêm sendo realizadas visando a propagação sexuada dessa espécie com resultados bastante satisfatórios (Carmona et al., 1994; Melchior et al., 2006). Entretanto, o desenvolvimento das plântulas é muito lento o que, associado à intensa predação dos frutos, representam limitação ao cultivo dessa espécie (Leitão Filho e Martins, 1981).
Um fator que influencia o processo germinativo da maioria das espécies é a temperatura, entretanto cada uma apresenta exigências próprias quanto a amplitude de valores. A temperatura ótima pode sofrer influência da espécie, da região de origem e de ocorrência e pode variar em função da condição fisiológica da semente (Alcalay e Amaral, 1981; Figliola e Kageyama, 1995).

As sementes de Campomanesia adamantium apresentam curta longevidade, devendo, portanto, serem utilizadas logo após a coleta. A germinação ocorre dos seis aos 27 dias após a semeadura, com média de 38\% (Machado et al., 1986). A germinação pode atingir médias mais altas se as sementes forem lavadas, tratadas com fungicidas e semeadas logo após a coleta dos frutos. Carmona et al. (1994) recomendaram a fermentação da mucilagem que recobre as sementes por dois a três dias, e observaram apenas $47 \%$ de germinação para a testemunha comparada a $100 \%$ quando a fermentação foi realizada utilizando hidróxido de amônio.

As sementes são classificadas como recalcitrantes, não tolerando o armazenamento a baixa temperatura e nem a dessecação, sendo que o armazenamento em frasco de vidro fechado a $25^{\circ} \mathrm{C}$ mantém a germinação em $60 \%$ por 30 dias (Melchior et al., 2006).

Como o desenvolvimento das plântulas é lento, estudos sobre a aplicação de fitoreguladores ou bioestimulantes de crescimento podem auxiliar o processo de produção de mudas de guavira. $\mathrm{O}$ emprego de reguladores de crescimento sobre a germinação e o crescimento das mudas de espécies frutíferas, de modo isolado, já vêm sendo desenvolvidos a algum tempo (Castro et al., 1991; Modesto et al., 1996; Ferreira, 1998; Leonel e Pedroso, 2005), e recentemente, em associação com outros reguladores e com o emprego de bioestimulantes (Ferreira et al, 2007), esses estudos têm aumentado.

Tratamentos com giberelina $\left(\mathrm{GA}_{3}\right)$ e citocinina, isolados ou em associação, promoveram aumentos significativos na germinação de sementes de Passiflora edulis f. flavicarpa e Passiflora alata (maracujá), entretanto, para Passiflora 
giberti as maiores porcentagens foram observadas com o emprego do etileno (Ferreira, 1998). Aumentos significativos na altura e número de folhas de plântulas de $P$. alata foram observados quando pulverizadas com $300 \mathrm{mg}$ $\mathrm{L}^{-1}$ de $\mathrm{GA}_{3}$, entretanto, não foram observadas diferenças para a porcentagem de emergência (Leonel e Pedroso, 2005). O efeito da giberelina baseia-se na ativação de enzimas hidrolíticas de reservas nutritivas disponibilizando para o embrião energia e compostos intermediários para o crescimento e desenvolvimento do mesmo, culminando com a germinação das sementes e emergência das plântulas. É percebido no alongamento do caule, comprimento dos entrenós, área foliar e acúmulo de matéria seca, uma vez que promovem a divisão e o alongamento celular ao promover o aumento da extensibilidade e da plasticidade da parede celular, devido à orientação transversal das microfibrilas de celulose, atuando preferencialmente em células jovens e meristemáticas (Stefanini et al., 2002; Kerbauy, 2004).

O emprego de bioestimulantes que contém em sua formulação a mistura de vários reguladores de crescimento pode incrementar o crescimento e desenvolvimento vegetal estimulando a divisão celular, a diferenciação e o alongamento das células (Castro et al., 1998). . Ferreira et al. (2007) observaram que as concentrações de 12 e $16 \mathrm{~mL}$ do bioestimulante Stimulate ${ }^{\circledR}$ por quilograma de sementes de maracujá ( $P$. edulis f. flavicarpa Deg.) promoveram as maiores porcentagens de emergência e desenvolvimento de plântulas.

Embora já seja possível encontrar algumas informações na literatura sobre a germinação de $C$. adamantium, ainda não foram encontrados dados sobre o crescimento das mudas. Diante do exposto, o objetivo neste trabalho foi avaliar o potencial germinativo das sementes de guavira em função de métodos de processamento, ambiente de incubação e épocas de semeadura após a extração dos frutos, bem como o desenvolvimento inicial das plantas sob efeito de bioestimulante.

\section{MATERIAL E MÉTODOS}

Os frutos de Campomanesia adamantium Camb foram colhidos no final do mês de novembro, a partir de diversas matrizes localizadas em região de cerrado na Fazenda Santa Madalena, nas seguintes coordenadas S $22^{\circ}$ $08^{\prime} 25^{\prime \prime} \mathrm{W} 55^{\circ} 08^{\prime} 17$ " na margem esquerda da rodovia BR 270, km 45, que liga Dourados a Itahum, em Mato Grosso do Sul. Os frutos foram levados para o Laboratório de Fisiologia Vegetal da Universidade Federal da Grande Dourados onde foram processados e as sementes extraídas.

\section{Germinação em função do processamento das sementes}

Foram realizados dois experimentos com processamento dos frutos e sementes. No primeiro, a semeadura foi realizada até três dias após a retirada dos frutos depois dos seguintes tratamentos: 1) extração das sementes, lavagem em água corrente para retirar o excesso de resíduo e secagem à temperatura ambiente sobre papel mata borrão durante três dias (seca por 3 dias); 2) extração seguida de lavagem em água corrente e semeadura logo em seguida à lavagem (lavada) e 3) extração das sementes dois dias após a colheita, lavagem e imersão em água por 24 horas (extraída + molho por 24 horas). No segundo experimento, a semeadura ocorreu após os seguintes tratamentos: 1) extração das sementes, lavagem em água corrente e secagem à temperatura ambiente sobre papel mata borrão durante nove dias; 2) extração das sementes dos frutos armazenados à temperatura ambiente por nove dias, lavagem em água corrente e semeadura logo em seguida e 3) extração das sementes dos frutos armazenados por oito dias, lavagem e imersão em água por 24 horas.

Em ambos os testes, a semeadura foi em caixas de plástico, tipo gerbox, sobre duas folhas de papel previamente umedecido com água destilada. A incubação foi realizada em câmara de germinação BOD nas temperaturas de $20 / 30^{\circ} \mathrm{C}$ com regime de 8 horas de escuro e 16 horas de luz, $18^{\circ} \mathrm{C}$ e $30^{\circ} \mathrm{C}$ sob luz constante, e em casa de vegetação sem controle de temperatura, em bandejas de célula de $3 \mathrm{~cm} \times 3 \mathrm{~cm}$ contendo plantmax ${ }^{\circledR}$ como substrato.

Durante 16 dias foi avaliado o número de sementes germinadas para calcular a porcentagem de germinação e o índice de velocidade de germinação (IVG) segundo Popinigis (1985). Ao final desse período, cinco plântulas por repetição foram amostradas para avaliar as massas de material fresco e seco das plântulas, após secagem em estufa de circulação forçada de ar a temperatura de $70^{\circ} \mathrm{C}$, até obtenção de massa constante. Foi considerada germinada a semente que apresentou protrusão da radícula superior a $1 \mathrm{~cm}$. Para cada experimento, o delineamento utilizado foi inteiramente casualizado, em esquema fatorial $3 \times 4$, (métodos de processamento e ambientes de incubação) com quatro repetições de 25 sementes.

\section{Crescimento inicial}

As plântulas com $1,5 \mathrm{~cm}$ restantes do experimento de germinação, provenientes da semeadura em casa de vegetação, foram transplantadas para embalagens de plástico de $15 \mathrm{~cm} \times 10 \mathrm{~cm}$ contendo terra+areia+cama-de- 
frango semidecomposta (1:1:1) (v:v). Após 15 e 25 dias do transplante, período correspondente a 80 e 90 dias após a semeadura (DAS), elas receberam duas aplicações dos seguintes tratamentos: 1$)$ bioestimulante $(0,2 \mathrm{~mL} /$ planta $) \mathrm{em}$ cada aplicação; 2) 3) e 4) ácido giberélico 50, 100 e 150mg $\mathrm{L}^{-1}(0,2 \mathrm{~mL} /$ planta) em cada aplicação e 5) testemunha (plantas sem nenhum tratamento).

Para a aplicação do bioestimulante e da giberelina foi utilizado frasco de spray adquirido no comércio de manipulação farmacêutica. O bioestimulante utilizado foi o produto comercial Stimulate ${ }^{\circledR}$ que contém reguladores vegetais como o ácido índolbutírico (Auxina) 0,005\%, cinetina (Citocinina) 0,009\% e ácido giberélico (Giberelina) $0,005 \%$ e também traços de sais minerais quelatizados (Stoller do Brasil, 1998).

Aos 110 DAS, as plantas foram avaliadas quanto à altura, diâmetro e número de folhas e aos 145 DAS quanto ao comprimento da raiz, massas de material fresco e seco da parte aérea e total e área foliar.
O experimento foi realizado em delineamento inteiramente casualizado com cinco tratamentos e quatro repetições de 15 mudas. Os resultados foram analisados pelo teste $\mathrm{F}$ e havendo significância, as médias foram comparadas pelo teste de Tukey a 5\% de probabilidade.

\section{RESULTADOS E DISCUSSÃO}

Não foi observada interação significativa entre métodos de processamento e ambiente de incubação para nenhuma característica avaliada nos dois experimentos (Tabelas $1 \mathrm{e}$ 2). Para a semeadura aos três dias após a retirada dos frutos, não foi observada diferença significativa na porcentagem e no índice de velocidade de germinação das sementes e nas massas de material fresco e seco das plântulas em função dos métodos de processamento (Tabela 1). Entre os ambientes de incubação das sementes, ocorreu variação significativa somente para o índice de velocidade de germinação que foi maior quando a incubação foi realizada a $30^{\circ} \mathrm{C}$.

TABELA 1. Porcentagem e índice de velocidade de germinação, massa de material fresco (MF) e seco (MS) de plântulas de Campomanesia adamantium com semeadura até três dias após a retirada dos frutos.

\begin{tabular}{lccll}
\hline \multicolumn{1}{c}{ Tratamentos } & Germinação (\%) & IVG & MF (mg) & MS (mg) \\
\hline Seca por 3 dias & $93,8 \mathrm{a}$ & $1,3 \mathrm{a}$ & $3,8 \mathrm{a}$ & $1,2 \mathrm{a}$ \\
Lavada & $92,7 \mathrm{a}$ & $1,6 \mathrm{a}$ & $4,0 \mathrm{a}$ & $1,3 \mathrm{a}$ \\
Extraída + molho 24 horas & $94,4 \mathrm{a}$ & $1,5 \mathrm{a}$ & $4,2 \mathrm{a}$ & $1,2 \mathrm{a}$ \\
\hline $18^{\circ} \mathrm{C}$ & $97,7 \mathrm{a}$ & $1,0 \mathrm{c}$ & $5,0 \mathrm{a}$ & $1,5 \mathrm{a}$ \\
$30^{\circ} \mathrm{C}$ & $100,0 \mathrm{a}$ & $3,1 \mathrm{a}$ & $3,7 \mathrm{a}$ & $1,3 \mathrm{a}$ \\
$20 / 30^{\circ} \mathrm{C}$ & $99,2 \mathrm{a}$ & $1,8 \mathrm{~b}$ & $3,3 \mathrm{a}$ & $0,8 \mathrm{a}$ \\
Casa de vegetação & $77,7 \mathrm{a}$ & $0,7 \mathrm{c}$ & $2,1 \mathrm{a}$ & $0,7 \mathrm{a}$ \\
\hline
\end{tabular}

Médias seguidas de mesma letra, na coluna, não variam significativamente entre si pelo teste de Tukey a 5\% de probabilidade

TABELA 2. Porcentagem e índice de velocidade de germinação, massa de material fresco (MF) e seco (MS) de plântulas de Campomanesia adamantium com semeadura 9 dias após a extração das sementes e armazenamento em ambiente.

\begin{tabular}{ccccl}
\hline Tratamentos & Germinação $(\%)$ & IVG & MF (mg) & MS (mg) \\
\hline $18^{\circ} \mathrm{C}$ & $2,94 \mathrm{a}$ & $0,02 \mathrm{ab}$ & $2,2 \mathrm{a}$ & $0,8 \mathrm{a}$ \\
$30^{\circ} \mathrm{C}$ & $3,69 \mathrm{a}$ & $0,06 \mathrm{a}$ & $1,8 \mathrm{a}$ & $0,7 \mathrm{a}$ \\
$20 / 30^{\circ} \mathrm{C}$ & $4,43 \mathrm{a}$ & $0,04 \mathrm{ab}$ & $1,6 \mathrm{a}$ & $0,4 \mathrm{a}$ \\
Casa de vegetação & $1,47 \mathrm{a}$ & $0,01 \mathrm{~b}$ & $1,1 \mathrm{a}$ & $0,3 \mathrm{a}$ \\
\hline
\end{tabular}

Médias seguidas de mesma letra, na coluna, não variam significativamente entre si pelo teste de Tukey a 5\% de probabilidade.

O processamento das sementes para retirada da mucilagem parece não ser fator decisivo na obtenção de altos índices de germinação dessa espécie. Resultados semelhantes foram observados por Melchior et al. (2006) que também 
obtiveram germinação acima de $80 \%$ em sementes de $C$. adamantium recém extraídas do fruto e com mucilagem. Os autores sugerem que essa mucilagem não apresenta substâncias inibidoras da germinação, contestando assim, a necessidade do processo de fermentação para retirada dessa mucilagem, conforme observado na literatura (Carmona et al., 1994).

Com a semeadura nove dias após a retirada das sementes dos frutos, embora em taxa muito baixa e menor velocidade, foi observada germinação apenas das sementes que foram secas durante esse período (Tabela 2). Não houve diferença significativa para a porcentagem de germinação, massas fresca e seca das plântulas entre as temperaturas de incubação, entretanto, observou-se que em casa de vegetação a germinação foi $66 \%$ menor que a $20 / 30^{\circ} \mathrm{C}$. Nesse mesmo ambiente, o IVG foi menor e a $30^{\circ} \mathrm{C}$ maior. As massas de material fresco e seco das plântulas também não variaram entre as temperaturas de incubação. Para as sementes que permaneceram nos frutos por 8 e 9 dias não foi observada germinação. Provavelmente, o estádio avançado de amadurecimento e senescência dos frutos tenham produzido algumasubstância tóxica ou inibidora do processo germinativo dessas sementes. Entretanto, resultados diferentes foram observados por Melchior et al. (2006), onde as sementes de C. adamantium colhidas em Presidente Prudente, São Paulo, semeadas logo após a retirada da mucilagem ou armazenadas em vidro a $25^{\circ} \mathrm{C}$ por 30 dias apresentaram germinação de 45 e $60 \%$ respectivamente. As menores médias de germinação foram das sementes armazenadas em vidro a $8^{\circ} \mathrm{C}(25 \%)$ e em saco de papel a $25^{\circ} \mathrm{C}(32 \%)$ pelo mesmo período.

Embora não tenha sido observada diferença significativa entre os tratamentos no experimento 1 , em ambos os experimentos (épocas de retirada das sementes do fruto), observou-se que, em geral, as plântulas provenientes da incubação a 30 e $18^{\circ} \mathrm{C}$ foram mais vigorosas, apresentando o dobro da massa seca. Entretanto, a germinação foi mais rápida a $30^{\circ} \mathrm{C}$ no experimento 1 , não variando nas condições de 18 e $20 / 30^{\circ} \mathrm{C}$ no experimento 2 . Em condição de casa de vegetação, o desenvolvimento aparentemente mais lento das plântulas pode ser atribuído à impossibilidade de controle das condições de umidade e temperatura nessa condição de cultivo.Avaliando o crescimento das plantas (Tabela 3), foi observado que a altura não variou entre os tratamentos, embora as plantas tratadas com giberelina $150 \mathrm{mg} \mathrm{L}^{-1}$ tenham apresentado altura média $40 \%$ maior que as plantas sem tratamento. Entretanto, ressalta-se o fato de que as mudas aos 145 DAS apresentavam ainda, em média $5,36 \mathrm{~cm}$ de altura, corroborando informações da literatura de que essa espécie apresenta crescimento lento (Leitão Filho e Martins, 1981).

TABELA 3. Altura, diâmetro e número de folhas de Campomanesia adamantium após aplicação de estimulantes de crescimento.

\begin{tabular}{lccc}
\hline Tratamentos & Altura $(\mathrm{cm})$ & Diâmetro $(\mathrm{mm})$ & Número de folhas \\
\hline Testemunha & $3,22 \mathrm{a}$ & $0,073 \mathrm{~b}$ & $10,20 \mathrm{ab}$ \\
Bioestimulante & $4,32 \mathrm{a}$ & $0,075 \mathrm{ab}$ & $10,80 \mathrm{a}$ \\
GA $50 \mathrm{mg} \mathrm{L}^{-1}$ & $3,42 \mathrm{a}$ & $0,081 \mathrm{ab}$ & $9,85 \mathrm{ab}$ \\
GA100 mg L & $4,26 \mathrm{a}$ & $0,093 \mathrm{a}$ & $11,05 \mathrm{a}$ \\
GA $150 \mathrm{mg} \mathrm{L}^{-1}$ & $5,36 \mathrm{a}$ & $0,078 \mathrm{ab}$ & $8,55 \mathrm{~b}$ \\
\hline Época de avaliação & & & $8,92 \mathrm{~b}$ \\
\hline 110 DAS* & $2,87 \mathrm{~b}$ & $0,05 \mathrm{~b}$ & $11,26 \mathrm{a}$ \\
\hline
\end{tabular}

Médias seguidas de mesma letra não variam significativamente entre si pelos testes $\mathrm{F}^{*}$ e Tukey a $5 \%$ de probabilidade.

O diâmetro foi maior nas mudas tratadas com giberelina $100 \mathrm{mg} \mathrm{L}^{-1}$, em relação à testemunha, embora não tenha variado significativamente das demais concentrações e das plantas tratadas com bioestimulante. O número de folhas das plantas foi menor quando tratada com giberelina $150 \mathrm{mg}$ $\mathrm{L}^{-1}$. Todas as características avaliadas foram maiores com a maior idade da planta.

O comprimento da raiz, assim como a altura da parte aérea, não variou significativamente entre os tratamentos. As características massas fresca e seca total e da parte aérea e área foliar foram significativamente maiores nas plantas tratadas com bioestimulante (Tabelas 3 e 4 ). 
TABELA 4. Comprimento da maior raiz (CR), massa fresca total (MFT), massa fresca da parte aérea (MFPA), massa seca total (MST), massa seca da parte aérea (MSPA) e área foliar de mudas de Campomanesia adamantium aos 145 DAS.

\begin{tabular}{|c|c|c|c|c|c|c|}
\hline Tratamentos & $\mathrm{CR}(\mathrm{cm})$ & MFT (mg) & MFPA (mg) & MST (mg) & MSPA(mg) & $\mathrm{AF}\left(\mathrm{cm}^{2}\right)$ \\
\hline Testemunha & $15,1 \mathrm{a}$ & $345 \mathrm{c}$ & $181 \mathrm{c}$ & $139 \mathrm{~b}$ & $65 \mathrm{~d}$ & $31,7 \mathrm{c}$ \\
\hline Bioestimulante & $16,9 \mathrm{a}$ & $584 \mathrm{a}$ & $431 \mathrm{a}$ & $238 \mathrm{a}$ & $153 \mathrm{a}$ & $65,3 \mathrm{a}$ \\
\hline GA $50 \mathrm{mg} \mathrm{L}^{-1}$ & $14,6 \mathrm{a}$ & $322 \mathrm{~d}$ & $178 \mathrm{c}$ & $132 \mathrm{c}$ & $82 \mathrm{~b}$ & $25,9 \mathrm{~d}$ \\
\hline GA100mg L ${ }^{-1}$ & $15,4 \mathrm{a}$ & $216 \mathrm{e}$ & $137 \mathrm{~d}$ & $061 \mathrm{e}$ & $43 \mathrm{e}$ & $35,4 \mathrm{~b}$ \\
\hline GA $150 \mathrm{mg} \mathrm{L}^{-1}$ & $13,7 \mathrm{a}$ & $354 \mathrm{~b}$ & $204 \mathrm{~b}$ & $128 \mathrm{~d}$ & $76 \mathrm{c}$ & $32,4 \mathrm{c}$ \\
\hline
\end{tabular}

Médias seguidas de mesma letra não variam significativamente entre si pelo teste de Tukey a 5\% de probabilidade.

Ferreira et al. (2007), ao aplicar doses de 0, 4, 8, 12, 16 e $20 \mathrm{~mL}$ de bioestimulante por quilograma de sementes de Passiflora edulis Sims.f. flavivcarpa Deg. (maracujá), observaram que sementes tratadas com 12 e $16 \mathrm{~mL}$ apresentaram maior germinação e maiores comprimento e diâmetro de caule, número de folhas, área foliar, maiores massa de material seco de folha, caule e raiz e comprimento de raiz. Os autores atribuem esses resultados, baseado em sua revisão, ao fato da auxina estimular o crescimento de caule, folhas e raízes e induzir a formação de raízes, e as citocininas estimularem a expansão foliar e, as auxinas e citocininas juntas, atuarem tanto no comprimento quanto no diâmetro do caule (Krikorian et al., 1987; Croizer et al., 2001; Taiz e Zeiger, 2004).

O bioestimulante, além de atuar nos processos de divisão e alongamento celular, pode também aumentar a absorção e a utilização dos nutrientes, atuando em diversos passos do metabolismo das plantas, inclusive no processo de germinação das sementes, sendo especialmente eficientes quando aplicados com fertilizantes foliares, e também compatíveis com defensivos (Castro et al., 1998; Lima et al., 2003).

O estudo da aplicação de ácido giberélico (GA) no presente trabalho se justificou uma vez que, os resultados em outras espécies também foram variáveis em função da dose utilizada. Resultados semelhantes foram observados por Stefanini et al. (2002) que, trabalhando as doses de 0, 10, 20 e 50 $\mathrm{mg} \mathrm{L}^{-1}$ de ácido giberélico em Lippia alba (Mill.) N.E. Brown (erva-cidreira), não observaram efeito significativo da GA sobre o crescimento das plantas, e justificaram seus resultados às concentrações dos fitorreguladores empregadas por eles.

Entretanto, o efeito benéfico da giberelina no crescimento de plântulas foi registrado por Modesto et al.
(1996), estudando o crescimento de plântulas de Citrus limonia Osbeck (limão cravo), quando observaram que as doses de 50 e $25 \mathrm{mg} \mathrm{L}^{-1}$ aumentaram o diâmetro do caule, porém o comprimento foi maior com a aplicação de $150 \mathrm{mg}$ $\mathrm{L}^{-1}$. Resultados semelhantes foram observados também por Castro et al. (1991), trabalhando com nogueira macadâmia (Macadamia integrifolia Maiden \& Betche) tratadas com 50, 100,250 e 500 $\mathrm{m} \mathrm{L}^{-1}$ via pulverização aos 120 e 181 dias após a semeadura, quando os autores observaram desenvolvimento do caule 15 dias após a pulverização.

Plântulas de Eugenia dysenterica D.C. (cagaiteira) apresentaram crescimento lento alcançando maior altura $(6,3 \mathrm{~cm})$ aos 182 dias após a semeadura em substrato areia+terra com ou sem esterco comparado a altura observada em substrato comercial plugmix $(3,2 \mathrm{~cm})$; comportamento semelhante também foi observado para o número de folhas e para a o índice de velocidade de emergência (Nietrsche et al., 2004). Os autores atribuíram o lento crescimento das plântulas a fatores genéticos, conforme sugerido também por Souza et al. (2002), ou a ausência de nutrientes no substrato, uma vez que eles não fizeram adubações de cobertura durante o experimento.

Baseado nessas observações da literatura, o lento crescimento da guavira pode também ser atribuído a fatores genéticos uma vez que as plântulas encontravam-se em substrato contendo terra e cama de frango semidecomposta. Os adubos orgânicos trazem grandes benefícios ao solo, pois além de conterem vários nutrientes minerais como $\mathrm{N}$, $\mathrm{P}$ e K, proporcionam maior capacidade de retenção de água, melhor estrutura, aeração e capacidade de ativar os processos microbianos (Khiel, 1985; Silva Júnior e Siqueira, 1997). A matéria orgânica no solo auxilia também na regulação da temperatura e retarda a fixação do $\mathrm{P}$ mineral e fornece produtos da decomposição orgânica que favorecem $\mathrm{o}$ 
desenvolvimento da planta (Novais e Smith, 1999).

\section{CONCLUSÕES}

A germinação das sementes aos três dias após a retirada do fruto é elevada e não varia em função do processamento e temperatura de incubação. Quando mantidas no fruto as sementes perdem viabilidade e vigor.

Considerando o lento crescimento das plantas de guavira, sugere-se que o tratamento hormonal com aplicação de bioestimulante é uma prática eficiente na produção de mudas dessa espécie.

\section{AGRADECIMENTOS}

À FUNDECT pelo apoio financeiro e ao CNPq pela concessão de bolsa.

\section{REFERÊNCIAS}

ALCALAY, N.; AMARAL, D.M.I. Descrição de plântulas de algumas essências florestais de interesse econômico para o Rio Grande do Sul. Rossiéria, v.4, n.1, p.85-100, 1981.

CARMONA, R.; REZENDE, L.P.; PARENTE, T.V. Extração química de sementes de gabiroba (Campomanesia adamantium Camb.). Revista Brasileira de Sementes, v.16, n.1, p.31-33, 1994.

CASTRO, P.R.C.; PACHECO, A.C.; MEDINA, C.L.; Efeitos de Stimulat e de micro-citros no desenvolvimento vegetativo e na produtividade da laranjeira 'pêra' (Citrus sinensis I. osbeck) Scientia Agricola, v.55, n.2, p.338-341, 1998.

CASTRO, P.R.C.; PENTEADO, S.R.; TERAMOTO, E.R. et al. Promoção do desenvolvimento de nogueira macadâmia com reguladores vegetais visando enxertia precoce. Anais Escola Superior de Agricultura “Luiz de Queiroz", Piracicaba, v.28, p.155-166, 1991.

CROIZER, A.; KAMIYA, K.; BISHOP, G.; YOKOTA, T. Biosymthesis of hormones and elicitor molecules. In: BUCHANAN, B.B.; GUISSEM, W.; RUSSEL, L.J. (Ed.) Biochemestry \& molecular biology of plants. Rockville: American Society of Plant Phisiologists, 2001. p.850-929.

FERREIRA, G. Estudo da embebição e do efeito de fitorreguladores na germinação de sementes de Passifloráceas. 1998. 139f. Tese(Doutorado em Horticultura) - Faculdade de Ciências Agronômicas, Universidade Estadual Paulista, Botucatu.
FERREIRA, G.; COSTA, P. N.; FERRARI, T. B.; RODRIGUES, J.D.; BRAGA, J.F.; JESUS, F. A. Emergência e desenvolvimento de plântulas de maracujazeiro azedo oriundas de sementes tratadas com bioestimulante. Revista Brasileira de Fruticultura, v.29, n.3, p.595-599, 2007.

FIGLIOLA, M. B.; KAGEYAMA, P. Y. Ecofisiologia de sementes de Inga uruguensis Hook. Et Arn. em condições de laboratório. Revista do Instituto Florestal, v.7, n.1, p.9199, 1995.

KERBAUY, G. B. Fisiologia vegetal. Rio de Janeiro: Guanabara Koogan, 2004. 452p.

KHIEL, E.J. Fertilizantes orgânicos. Piracicaba: Agronômica Ceres, 1985. 492 p.

KRIKORIAN, A.D.; KELLY, K.; SMITH, D.L. Hormones in tissue culture and micropropagation, In: DAVIES, P.J. (Ed.). Plants hormones and their role in plant growth and development. Dordrecht: Martinus Nijhoff, 1987. p. 593-613.

LEITÃO FILHO, H.F.; MARTINS, F.R. Espécies de Cerrado com potencial em fruticultura. In: CONGRESSO ANUAL DA SOCIEDADE AMAERICANA DE CIÊNCIAS HORTÍCOLAS, 29., 1981, Campinas. Anais ... Campinas: ASHS, 1981. p.29.

LEONEL, S.; PEDROSO, C. J. Produção de mudas de maracujazeiro-doce com o uso de biorregulador. Revista Brasileira de Fruticultura, v.27, n.1, p.107-109, 2005.

MACHADO, J.W.B.; PARENTE, T.V.; LIMA, R.M. Informações sobre a germinação e características físicas das sementes de fruteiras nativas do Distrito Federal. Revista Brasileira de Fruticultura, v.8, n.2, p.59-62, 1986.

MARTINS, S. V.; SILVA, N. R. S. Considerações sobre conservação e restauração de fragmentos florestais. Folha Florestal, n. 99, p. 7- 8, 2001.

MELCHIOR, S.J.; CUSTÓDIO, C.C.; MARQUES, T.A.; MACHADO NETO, N.B. Colheita e armazenamento de sementes de gabiroba (Campomanesia adamantium Camb. Myrtaceae) e implicações na germinação. Revista Brasileira de Sementes, v.28, n.3, p.141-150, 2006.

MODESTO, J.C.; RODRIGUES, J.D.; PINHO, S.Z. Efeito do ácido giberélico sobre o comprimento e diâmetro do caule de plântulas de limão " cravo" (Citrus limonia Osbeck). Scientia Agricola, v.53, n.2-3, p. 332-337, 1996.

NIETRSCHE, S.; GONÇALVES, V.D.; PEREIRA, M.C.T.; SANTOS, F.A.; ABREU, S.C.; MOTA, W.F. Tamanho da semente e substratos na germinação e crescimento inicial de mudas de cagaiteira. Ciência e Agrotecnologia, v.28, n.6, 
p.1321-1325, 2004.

NOVAIS, R.; SMYTH, T. J. Fósforo em solo e planta em condições tropicais. 1 ed. Viçosa: UFV, 1999. 339p.

PENNA, M. Dicionário brasileiro de plantas medicinais: descrição das plantas medicinais indígenas e das exóticas aclimatadas no Brasil. 3. ed. São Paulo: Livraria Kosmos Editora, 1946. 409 p.

RODRIGUES, V.E.G.; CARVAlHO, D.A. Plantas medicinais no domínio dos cerrados. Lavras: Ed.UFLA, 2001. 180p.

SILVA JUNIOR, J.P.; SIQUEIRA, J.O. Aplicação de formononetina sintética ao solo como estimulante da formação de micorriza no milho e na soja. Revista Brasileira de Fisiologia Vegetal, v.9, n.1, p.35-41, 1997.
SOUZA, E.B.; NAVES, R.V.; CARNEIRO, I.F.; LEANDRO, W.M.; BORGES, J.D. Crescimento e sobrevivência de mudas de cagaiteira (Eugenia dysenterica DC) nas condições do cerrado. Revista Brasileira de Fruticultura, v.24, n.2, p.491-494, 2002.

STEFANINI, M. B.; RODRIGUES, S. D.; MING, L. C. Ação de fitorreguladores no crescimento da erva-cidreirabrasileira. Horticultura Brasileira, v.20, n.1, p.18-23, 2002.

STOLLER DO BRASIL. Stimulate Mo em hortaliças. Cosmópolis: Stoller do Brasil- Divisão Arbore, 1998. 1v. (Informativo Técnico).

TAÍZ, L.; ZEIGER, E. Fisiologia vegetal. 3 ed. Porto Alegre: Artmed, 2004. 719p. 